\title{
EFFECT OF PLASTICIZERS ON THE PHYSICOCHEMICAL PROPERTIES OF BIOPLASTIC EXTRACTED FROM BANANA PEELS
}

\author{
Khagendra Chapain ${ }^{1}$, Sambridhi Shah ${ }^{1}$, Binod Shrestha ${ }^{1}$, Rajendra Joshi ${ }^{1}$, Naresh Raut ${ }^{1}$, Rajesh \\ Pandit ${ }^{1,2 *}$ \\ ${ }^{1}$ Department of Chemistry, Tri-Chandra Multiple Campus, Tribhuvan University, Kathmandu, Nepal \\ ${ }^{2}$ Nepal Polymer Institute, Kathmandu, Nepal \\ *Corresponding email: panditrajesh02@gmail.com
}

(Received: July 29, 2021; Revised: December 02, 2021; Accepted: December 10, 2021)

\begin{abstract}
Plasticizers are the binding substances used to increase the elasticity of materials. In this research work, bioplastic is extracted from banana peels using various plasticizers such as, glycerol, urea, distilled water and glucose. The prepared bioplastics were characterized by using Fourier-transform infrared spectroscopy (FTIR) spectroscopic analysis which showed that the peak at $3355 \mathrm{~cm}^{-1}$ indicate the H-bonding formation between N-H urea and starch. The physicochemical properties such as water absorption test, soil decomposition and load test of synthesized bioplastics were analyzed at ambient temperature. The water uptake analysis showed that bioplastic absorbs water for up to 4 days without being decay. The load test showed that urea plasticized bioplastic has a high tensile strength of $2.3 \mathrm{KPa}$. The result revealed that the bioplastic with glucose as a plasticizer showed the effective result in water uptake and soil decomposition test whereas the urea plasticized bioplastic showed relatively good tensile strength.
\end{abstract}

Keywords: Absorption, bioplastics, glucose, glycerol, plasticizers

\section{INTRODUCTION}

Bioplastics are the plastics formed from renewable biomass and can easily be compostable in nature (Folino $\mathrm{et}$ al., 2020). The biomass generally includes the raw materials like vegetable fats \& oil, straw, saw dust, wood chips, agricultural waste, food waste, etc. Among them, banana peels are common wastes which contain high amount of starch and organic material with abundant availability, cost effective and eco-friendly properties, thus widely used for the production of bioplastics (Padam et al., 2014). The bioplastics extracted from banana peels instead of petroleum-based plastic is an effective solution leading to reduction in use of non-renewable raw materials (Kadam \& Datta, 2020). For the synthesis of bioplastics, plasticizers must be added to improve the flexibility, processability, workability and distensibility of polymers by lowering the glass transition temperature (Tg) (Vieira et al., 2011), whereas without plasticizer, the film is found brittle and showed poor physical properties (Sirviö et al., 2018). The plasticizer is significant compatibilized the polymer for effective plasticization, and enhance various parameters, including polarity, hydrogen bonding, dielectric constant, and solubility parameters (Tyagi \& Bhattacharya, 2019). Plasticizers containing hydroxyl groups will form hydrogen bonds with biopolymers, improving the workability and durability with decreasing bioplastics' rigidity, which further increases the flow and thermo-plasticity (Vieira et al., 2011). Among the various plasticizers such as glucose (Stark et al., 2005), urea (Ma et al., 2004), sorbitol (Felix et al., 2016), glycerol (Inayati \& Matovanni, 2019), phthalate ester (Park et al., 2004), sebacic acid (Jia et al., 2018), and azelaic acid (Dibenedetto et al., 2016) etc. are used as a plasticizer for binding bioplastics. Since most plasticizers contain hydrophilic groups, these compounds can interact by means of hydrogen bonds with polymer matrix. Many studies have been carried out on different plasticizers to evaluate their performance, being polyols especially glycerol and glucose are the most commonly used (Versino \& García, 2018). Similarly, urea exhibits a strong hydrophilicity due to its chemical structure, containing two amino groups and one carbonyl group and a tendency to crystallize therefore it is used for plasticization of starch containing bioplastics (Ma et al., 2006). Several research have been conducted using different plasticizer separately in starch-based material but no research addressing comparative study of different plasticizer on physicochemical properties of bioplastic synthesized from banana peels.

In this work glycerol, glucose, distilled water and urea are used as a plasticizer in order to study and compare their physicochemical properties such as water uptake, biodegradability and tensile strength.

\section{MATERIALS AND METHODS}

\section{Materials}

The samples green banana (Musa acuminate) peels were bought from local markets of Kathmandu, Nepal. The chemicals used in the experiments are hydrochloric acid $(36 \%)$, sodium hydroxide $(97 \%)$, sodium metabisulphate (97\%), glucose (99\%), glycerol (99\%) and urea (99\%) were manufactured by Fisher scientific, India and supplied from local suppliers in Kathmandu which were used without further purification. 


\section{Methods \\ Preparation of banana paste}

The banana peels were collected, washed, cut into small pieces, and soaked with sodium metabisulphite $(1 \%)$ for about 45 minutes to prevent browning of paste by avoiding enzymatic reaction (Fig. 1). The peels were grinded in paste form using the grinder for two minutes and then sieved using 50 mesh sieves. Thus, obtained paste was washed with $95 \%$ ethanol in order to remove the $\mathrm{Na}_{2} \mathrm{~S}_{2} \mathrm{O}_{5}$ (Gaonkar et al., 2018).

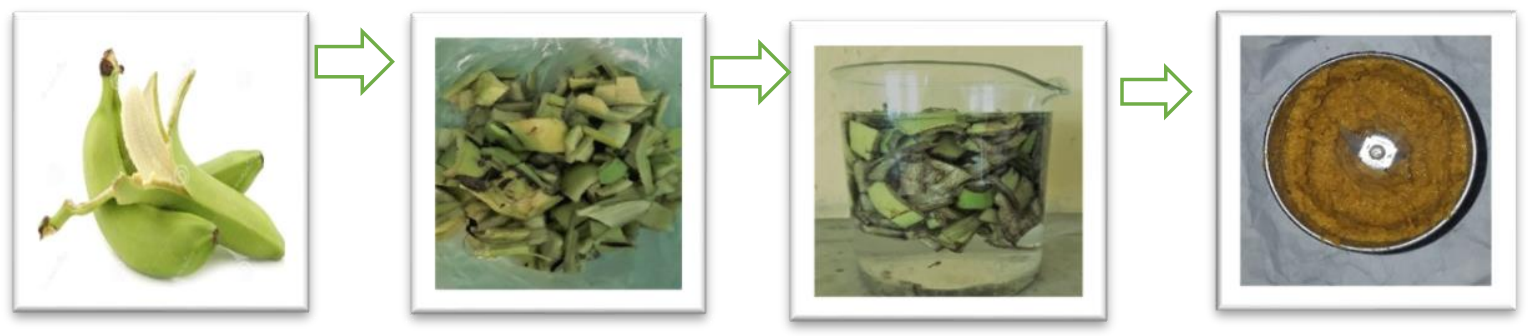

Figure 1. Steps involving in preparation of banana paste.

\section{Preparation of bioplastics}

Different plasticizers, i.e., glycerol, urea, glucose, and distilled water, were taken to prepare four different bioplastics (Fig. 2). Three $\mathrm{mL} 0.5 \mathrm{M} \mathrm{HCl}, 2 \mathrm{~mL}$ of respective plasticizer, and $3 \mathrm{~mL}$ of $0.5 \mathrm{M} \mathrm{NaOH}$ were added in $12 \mathrm{~mL}$ of banana paste. To aid the process of film formation by breaking $\mathrm{H}$ - bonding amongst the chain of glucose in starch, HCL was used for the hydrolysis of amylopectin. Similarly, $\mathrm{NaOH}$ was added to neutralize the acidity of the mixture and respective plasticizers were added to aid processing and for improving film flexibility. The mixture was stirred and transferred to petri discs for the heating oven at $130{ }^{\circ} \mathrm{C}$ for 30 minutes. After the heating, the samples were placed for drying for two days at room temperature (Gaonkar et al., 2018).

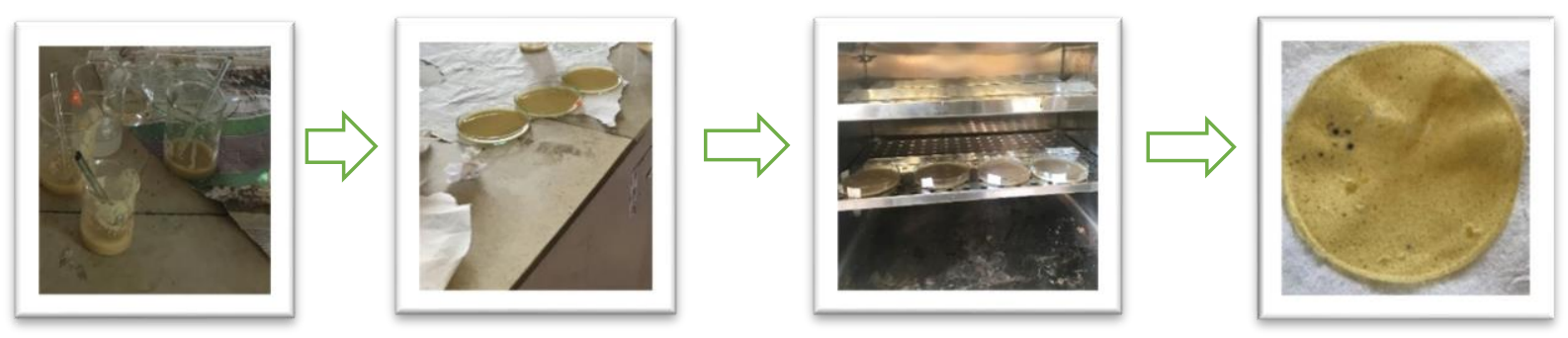

Figure 2. Steps showing the preparation of bio-plastics from banana peel.

\section{Fourier transform infrared (FTIR) spectroscopy}

The functional group analysis of the sample was identified using FTIR spectroscopic by producing an optical signal with all the IR frequencies encoded into it. The FTIR analysis was carried out in the Department of Plant Resources, Thapathali, Kathmandu, Nepal, using an IR prestige-21 FTIR spectrometer (SHIMADZU). The spectra were collected in a spectral range of $4000-400 \mathrm{~cm}^{-1}$.

\section{Water uptake test}

Each sample was cut into $1 \mathrm{~cm} \times 3.5 \mathrm{~cm}$ size, and then the weight of each sample was taken. After that, the sample was placed into a beaker containing $50 \mathrm{~mL}$ of water at room temperature. The sample was then taken out from the water after 1 hour and the regular interval time of 2 hours. The sample was wiped off, and the final weight was recorded. The amount of water uptake was calculated by using the following formula (Prashar \& Kumar, 2012);

Water absorption $=\frac{W_{2}-W_{1}}{W_{1}} \times 100 \%$. where, $\mathrm{w}_{1}=$ initial weight of sample, $\mathrm{w}_{2}=$ final weight of sample

\section{Soil burial test}

The small piece of film was cut and weighed, then the piece was kept in the beaker containing soil at a depth of $5 \mathrm{~cm}$ from the surface. The weight of each specimen was measured at a regular interval of 4 days to note the degradation process up to 80 days. The same procedure was carried out for all the samples. Here, the percentage of weight reduction and the rate of biodegradation of each sample were calculated using the following equations (Gautam \& Kaur, 2013; Fatimah \& Wan, 2017).

$\%$ Reduction of weight $=\frac{W_{2}-W_{1}}{W_{1}} \times 100 \%$

Rate of biodegradation $=\frac{W_{2}-W_{1}}{\text { maximum time of degradation }}$ (ii) 


\section{Load test}

A small piece of the bioplastic was cut into $2 \mathrm{~cm} \times 6 \mathrm{~cm}$ size and the thicknesses were measured by using micrometer screw gauze and the length was taken by the help of scale. At the same time weight of sample was noted by electronic balance. A spring balance was hooked onto the middle of the bioplastic and load was added until the sample broke apart. The strength was calculated by using formula (Fatimah \& Wan, 2017);

Tensile strength $=\frac{\text { Weight load }(N)}{\text { length } \times \text { thickness }}$ $=\frac{\text { Weight load }(\mathrm{N})}{\text { Cross section Area }\left(\mathrm{mm}^{2}\right)} \ldots \ldots \ldots \ldots$ (ii)

\section{RESULTS AND DISCUSSION}

FTIR spectroscopic analysis of bioplastics

Functional group analysis of the starch-based bioplastics synthesized from urea (UBP), Glycerol (GLBP), distilled water (DBP), and glucose (GBP) as plasticizers and FTIR spectra are shown in Fig. 3.

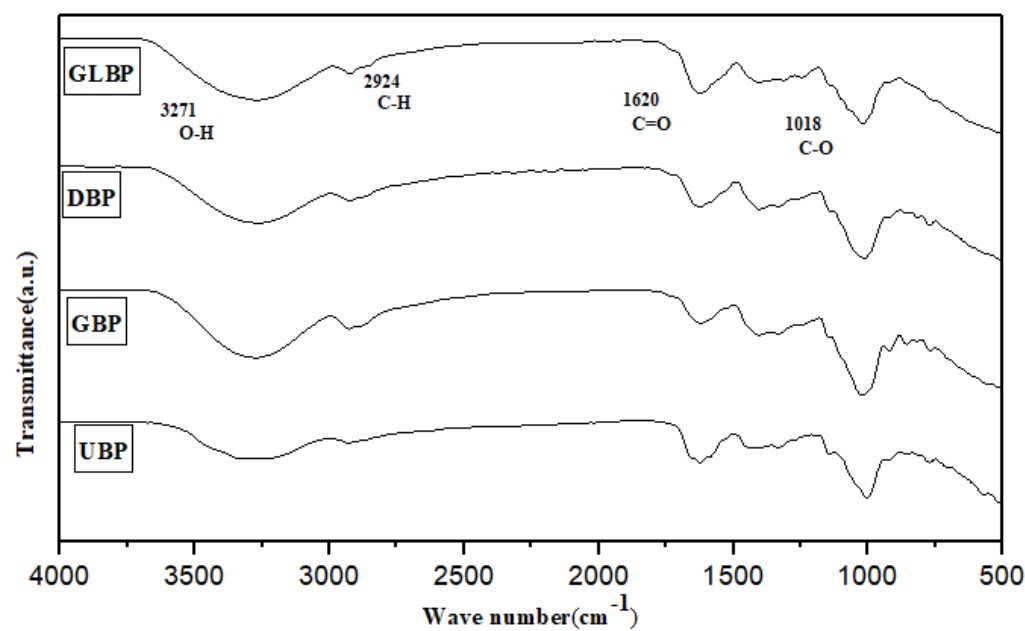

Figure 3. FTIR spectra of starch-based bioplastics of GLBP, DBP, GBP and UBP.

In Fig. 3, the peak obtained at $3271 \mathrm{~cm}^{-1}$ represents the $\mathrm{O}$ $\mathrm{H}$ group's strong absorption due to $\mathrm{O}-\mathrm{H}$ stretching characteristics. Similarly, the occurrence of $\mathrm{C}-\mathrm{H}$ vibrational stretching resulted in a sharp peak at $2924 \mathrm{~cm}^{-1}$. Moreover, the peak at $1620 \mathrm{~cm}^{-1}$ showed a $\mathrm{C}=\mathrm{O}$ bond, and the peak at $1627 \mathrm{~cm}^{-1}$ indicated $\mathrm{OH}$ deflection which was due to hydroxyl group bending mode in a water molecule. Likewise, the strong absorption peak at $1018 \mathrm{~cm}^{-1}$ corresponds the C-O-C bond stretching in the anhydrous glucose ring that developed because of starch (Prashar \& Kumar, 2012). The peak at $1350 \mathrm{~cm}^{-1}, 1480 \mathrm{~cm}^{-1}$ assigned to $\mathrm{CH}_{2}$ bending vibrations in bioplastics. The peak obtained at the region below $800 \mathrm{~cm}^{-1}$ attributed to the pyranose ring skeletal vibration in the glucose unit. The peak at $3355 \mathrm{~cm}^{-1}$ was associated with H-bonding formation between of $\mathrm{N}-\mathrm{H}$ in urea and starch in urea plasticized bioplastic (Rinaldi et al., 2015).

\section{Water uptake analysis}

The water absorption test was carried out for 96 hours to investigate the water uptake properties of GLBP, UBP, DBP, GBP as shown in the Fig. 4.
The Fig. 4 showed that the variation of weight gained of bioplastic against time. The initial weight of glycerol plasticized bioplastic was $0.35 \mathrm{~g}$, and after 1 hour, the weight gain reached $1.5 \mathrm{~g}$. The gradual weight gain was recorded, and finally, after 78 hours, the weight gain was found at $1.76 \mathrm{~g}$. The result indicated that the water uptake was fast in the initial stage, while after the particular time, the amount of water uptake increased slowly. Similar nature of weight gain by urea, distilled water, and glucose plasticized bioplastic was recorded. The most negligible weight gain was measured in glucose plasticized bioplastics which indicated that the glycerol plasticized bioplastic showed a significant amount of water absorption, whereas the urea, distilled water, and glucose plasticized bioplastics showed low water absorption. This is due to the trihydric nature of glycerol which formed a hydrogen bond with water (Prashar \& Kumar, 2012). The glucose-plasticized bioplastic absorbed less water than others because of a smooth surface without pores, and the bioplastic film is more robust. The glucose plasticizer can absorb water for four days without being decay. The swelling of bioplastic is higher at initial hours and continuously decreases up to equilibrium. 


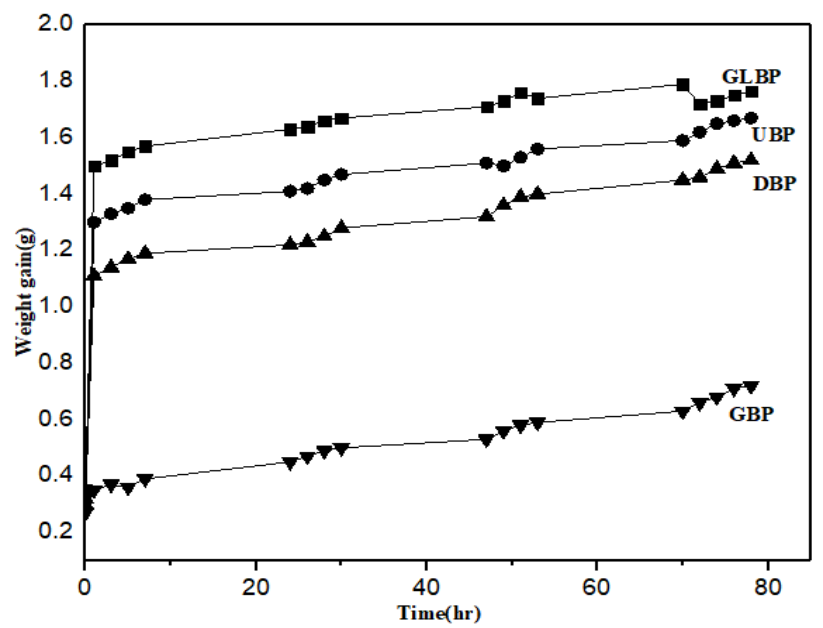

Figure 4. The water absorbability of bioplastics plasticized by different plasticizer (GLBP, UBP, DBP and GBP).

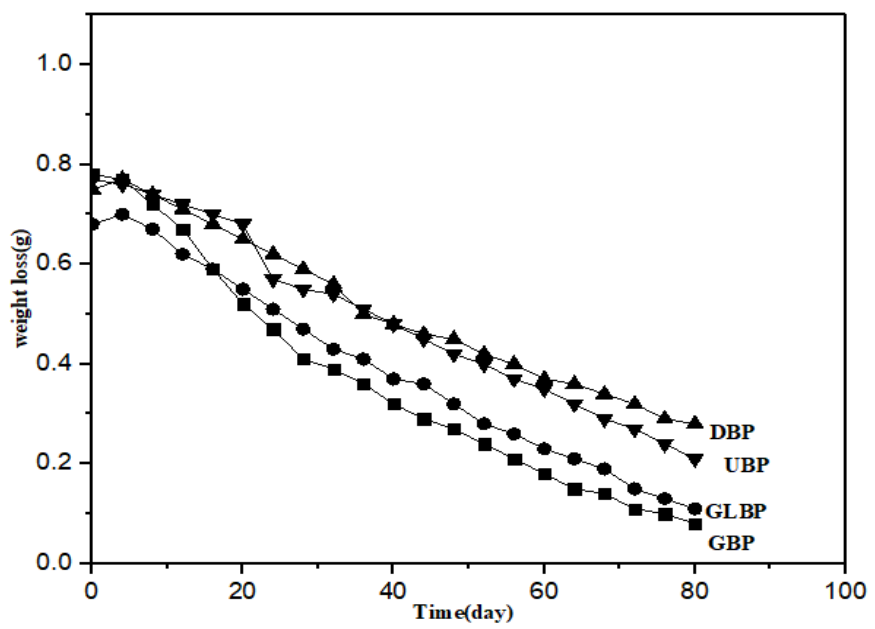

Figure 5. Soil decomposition test of different plasticized starch-based bioplastics (DBP, UBP, GLBP and GBP).

\section{Soil Decomposition Test}

The soil decomposition test was carried out for 80 days to analysis decomposition pattern of GLBP, UBP, DBP, GBP as shown in the Fig. 5.

The plot of weight loss of different plasticized bioplastics $\mathrm{v} / \mathrm{s}$ time was illustrated in Fig. 5. From the plot, the initial weight of GBP was $0.78 \mathrm{~g}$. After four days, the weight was increased to $0.79 \mathrm{~g}$ and started to decrease after eight days and was found to $0.75 \mathrm{~g}$ and completely degrade in 80 days. In GLBP, the weight increased to $0.70 \mathrm{~g}$ after four days and decreased to $0.67 \mathrm{~g}$ after eight days, indicating the degradation of bioplastic and degradation period was found to be more than GBP. UBP and DBP also followed a similar pattern of degradation. The gradual degradation of bioplastic was noticed after 16 days, and it started to break into tiny fragments after 20 days. The glucose plasticized bioplastic decayed almost $95 \%$ in 80 days, whereas distilled water plasticized bioplastic decayed only $70 \%$. The decomposition patterns of GBP, UBP, GLBP, and DBP was:

$$
\mathrm{DBP}<\mathrm{UBP}<\mathrm{GLBP}<\mathrm{GBP}
$$

The rate of decomposition of bioplastic depends upon the H-bonding capability per molecule of plasticizer. Glucose plasticized bioplastic has low H-bonding capability, so it decomposes faster than the rest of the other (Emadian et al., 2017).

\section{Load test}

Load test measurement was carried out to determine the force to hold something until it breaks. The bar diagram of synthesized bioplastic using different plasticizer such as glycerol, glucose and urea on the tensile strength is shown in Fig. 6. 


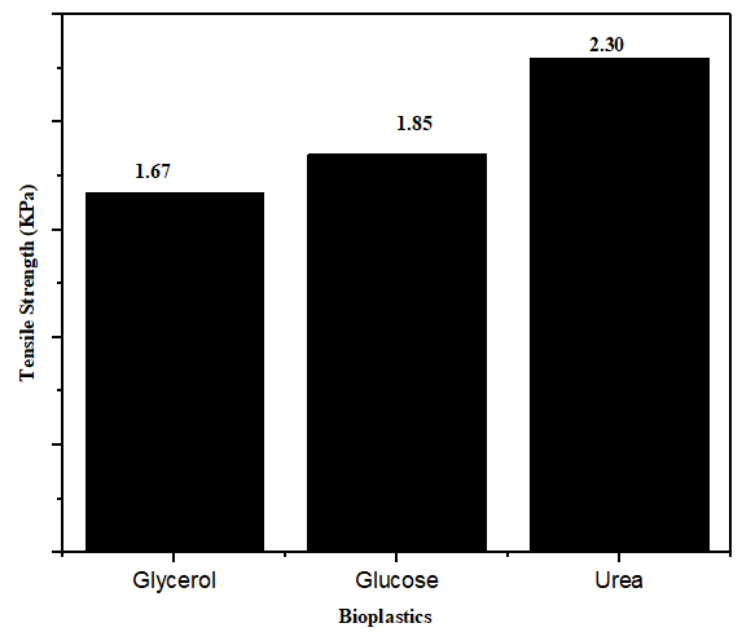

Figure 6. The tensile strength of glycerol, glucose and urea plasticized bioplastics.

Figure 6 shows the tensile strength of glycerol, glucose and urea plasticized bioplastics. The tensile strength of glycerol bioplastic was $1.67 \mathrm{KPa}$ whereas glucose and urea plasticized bioplastics were found $1.85 \mathrm{KPa}$ and $2.30 \mathrm{KPa}$, respectively. The decrease in tensile strength from urea to glycerol is due to lowering the intra-molecular attraction between the starch chains and promoting the formation of $\mathrm{H}$-bonds between plasticizer and starch molecules. Thus, it reduces the tensile strength of bioplastics by subsequently weaking the H-bonding between starch chains (Bourtoom, 2008).

\section{CONCLUSIONS}

In this work, bioplastics using glycerol, urea, distilled water and glucose were successfully synthesized from banana peels respectively. The FTIR spectra of peak at $1620 \mathrm{~cm}^{-1}$ indicate the presence of amide groups, peak at $3355 \mathrm{~cm}^{-1}$ in UBP associated to $\mathrm{H}$-bonding formation of $\mathrm{N}-\mathrm{H}$ in urea and starch in UBP. The GBP showed low water absorption than UBP, GLBP and DBP. Biodegradation studies conclude that the GBP has greater rate of degradation than UBP, and DBP. The UBP showed high tensile strength of $2.3 \mathrm{KPa}$ than GLBP and GBP.

\section{ACKNOWLEDGEMENTS}

Authors would like to acknowledge Department of Plant Resources Thapathali, Kathmandu for FTIR spectroscopic analysis.

\section{AUTHOR CONTRIBUTIONS}

Study conception and design: RP, KC; data collection: NR; analysis and interpretation of results: $\mathrm{KC}, \mathrm{BS}, \mathrm{SS}$; draft manuscript preparation: RP, KC, RJ. All authors reviewed the results and approved the final version of the manuscript.

\section{CONFLICT OF INTEREST}

The authors declare no conflict of interest pertinent to this work.

\section{DATA AVAILABILITY STATEMENT}

The datasets generated during and/or analyzed during the current study are available from the corresponding author on reasonable request.

\section{REFERENCES}

Bourtoom, T. (2008). Plasticizer effect on the properties of biodegradable blend from rice starch-chitosan. Songklanakarin Journal of Science and Technology, 30, 149-155.

Dibenedetto, A., Colucci, A., \& Aresta, M. (2016). The need to implement an efficient biomass fractionation and full utilization based on the concept of "biorefinery" for a viable economic utilization of microalgae. Environmental Science and Pollution Research, 23(22), 22274-22283. http://dx.doi.org/10 .1007/s11356-016-6123-5.

Emadian, S.M., Onay, T.T., \& Demirel, B. (2017). Biodegradation of bioplastics in natural environments. Waste Management, 59, 526-536. http://dx.doi.org/10.1016/j.wasman.2016.10.006.

Fatimah, N., \& Wan, L. (2017). Bioremediation science and technology the development of banana peel / corn starch bioplastic film: A preliminary study. Bioremediation Science and Technology 5(1), 12-17.

Felix, M., Carpintero, V., Romero, A., \& Guerrero, A. (2016). Influence of sorbitol on mechanical and physico-chemical properties of soy protein-based bioplastics processed by injection molding. Polimeros, 26(4), 277-281.

Folino, A., Karageorgiou, A., Calabrò, P.S., \& Komilis, D. (2020). Biodegradation of wasted bioplastics in natural and industrial environments: A review. Sustainability (Switzerland), 12(15), 137.

Gaonkar, M.R, Palaskar, P., \& Navandar, R. (2018). Production of bioplastic from banana peels. International Journal of Advances in Science Engineering and Technology, 6(1), 36-38.

Gautam, N., \& Kaur, I. (2013). Soil burial biodegradation studies of starch grafted polyethylene and identification of Rhizobium meliloti therefrom. Journal of Environmental Chemistry and Ecotoxicology, 5, 147-158.

Inayati, D.J.P., \& Matovanni, M.P.N. (2019). Effect of glycerol concentration on mechanical characteristics of biodegradable plastic from rice straw cellulose. AIP Conference Proceedings 2097.

Jia, P., Xia, H., Tang, K., \& Zhou, Y. (2018). Plasticizers derived from biomass resources: A short review. Polymers, 10(12), 1303. https://doi.org/10.3390/polym10121303. 
Kadam, P., \& Datta, S. (2020). Production of biodegradable plastic from banana peel. International Journal of Innovative Research in Science, Engineering and Technology, 9(7), 6177-6185.

Ma, X.F., Yu, J.G., \& Feng, J. (2004). Urea and formamide as a mixed plasticizer for thermoplastic starch. Polymer International, 53(11), 1780-1785.

Ma, X.F., Yu, J.G., \& Wan, J.J. (2006). Urea and ethanolamine as a mixed plasticizer for thermoplastic starch. Carbobydrate Polymers, 64(2), 267-273.

Padam, B.S., Tin, H.S., Chye, F.Y., \& Abdullah, M.I. (2014). Banana by-products: An under-utilized renewable food biomass with great potential. Journal of Food Science and Technology, 51(12), 3527-3545.

Park, H.M., Misra, M., Drzal, L.T., \&. Mohanty, A.K. (2004). Green' nanocomposites from cellulose acetate bioplastic and clay: Effect of eco-friendly triethyl citrate plasticizer. Biomacromolecules, 5(6), 2281-2288.

Prashar, D., \& Kumar, S. (2012). Synthesis, characterization and evaluation of physical properties of biodegradable composites from corn starch. Journal of Pharmacognosy and Phytochemistry, $1(2), 20-26$.

Rinaldi, W., Lubis, M.R., \& Fathanah, U. (2015). Biodegradable plastic from cassava waste using sorbitol as plasticizer. Proceedings of the $5^{\text {th }}$ Annual International Conference Syiah Kuala University (pp. 62-66), Darussalam, Indonesia.

Sirviö, J.A., Visanko, M., Ukkola, J., \& Liimatainen, H. (2018). Effect of plasticizers on the mechanical and thermomechanical properties of cellulose-based biocomposite films. Industrial Crops and Products, 122, 513-521.

Stark, T.D., Choi, H., \& Diebel, P.W. (2005). The influence of molecular weight on plasticizer retention a key change to specification PGI-1104 improves understanding of long-term PVC geomembrane performance. GFR Magazine, 23(2), 1-6.

Tyagi, V., \& Bhattacharya, B. (2019). Role of plasticizers in bioplastics. MOJ Food Processing Technology, 7(4), 128-130.

Versino, F., \& García, M.A. (2018). Starch films for agronomic applications: comparative study of urea and glycerol as plasticizers. International Journal of Environment, Agriculture and Biotechnology, 3(5), 1854-1864.

Vieira, M.G.A., da Silva, M.A., dos Santos, L.O., \& Beppu, M.M. (2011). Natural-based plasticizers and biopolymer films: A review. European Polymer Journal, 47(3), 254-263. http://dx.doi.org/10.1016/j.eurpolymj.2010.12.011. 